\title{
Oligodendrocytes Arrest Neurite Growth by Contact Inhibition
}

\author{
Christine Bandtlow, Thomas Zachleder, and Martin E. Schwab \\ Brain Research Institute, University of Zurich, 8029 Zurich, Switzerland
}

\begin{abstract}
We have used video time-lapse microscopy to analyze in vitro the interactions of growth cones of newborn rat dorsal root ganglion cells with dissociated young rat CNS glial cells present in the cultures at low density. To provide optimal conditions for neurite extension, cells were grown on laminin and in NGF-supplemented medium. Our initial observations showed that there are 2 subpopulations of growth cones differing in their growth rate on laminin (averages of 12 and $45 \mu \mathrm{m} / \mathrm{hr}$ ). When these growth cones encountered astrocytes, they maintained their normal configuration and growth velocity. They subsequently grew along or on top of astrocytes. In some cases, however, fast-moving growth cones showed a slight reduction in their growth rate. When growth cones countered oligodendrocytes, however, firm filopodial contact was sufficient to induce a rapid and long-lasting arrest of the growth cone motility, often followed by a collapse of the growth cone structure. One third of the paralyzed growth cones were observed to retract. Growth arrest and growth cone collapse were strictly dependent on membrane contact between neurons and oligodendrocytes. This contact inhibition phenomenon was exclusively found with differentiated oligodendrocytes and could be prevented by the monoclonal antibody $\mathbb{I N}-1$ directed against neurite growth inhibitors NI-35 and NI-250 (Caroni and Schwab, 1988b). These results confirm previous findings that the neurite growth inhibitor proteins are important in axon outgrowth. Further, the inhibition of neurite growth exerted by oligodendrocytes is a contact-mediated phenomenon that can be triggered by the tip of growth cone filopodia.
\end{abstract}

Neurite growth in both developing and regenerating nervous systems is crucially influenced by the location of a nerve cell and the environment encountered by its axon. Soluble molecules such as trophic and tropic factors, and direct membrane contacts with non-neuronal cells, other neurites, or with the extracellular matrix, can support and direct axonal growth in the CNS and PNS. A growing number of cell adhesion and substrate molecules have been identified in the vertebrate (reviewed by Jessel, 1988; Rutishauser and Jessel, 1988) and invertebrate nervous systems (reviewed by Anderson, 1988). In vitro and some in

\footnotetext{
Received Feb. 21, 1990; revised July 26, 1990; accepted July 27, 1990.

We wish to thank Drs. D. Cadelli, P. Paganetti, and R. Colello for helpful comments on the manuscript and R. Schoeb and R. Emch for help with the drawings and photographs. This study was supported by Swiss National Science Foundation Grants 3.043-084 and 3.065-087, the Dr. E. Slack Gyr Foundation (Zurich), the Swiss Multiples Sclerosis Society, Regeneron Pharmaceuticals (Tarrytown, NY), and the American Paralysis Association.

Correspondence should be addressed to Dr. Christine Bandtlow, Brain Research Institute, University of Zurich, August-Forelstrasse 1, 8029 Zurich, Switzerland. Copyright (C) 1990 Society for Neuroscience $0270-6474 / 90 / 123837-12 \$ 03.00 / 0$
}

vivo studies have shown that antibodies against such molecules can disrupt cell migration, neurite growth, fasciculation of neurites, and interactions between specific cell types (Rutishauser et al., 1978; Edelman, 1986; Rathjen et al., 1987; Kunemund et al., 1988; Moos et al., 1988). Very recently, constituents with repulsive or inhibitory effects on neurite growth or cell adhesion are being found in the developing and adult nervous systems (Caroni and Schwab, 1988a; Cox et al., 1990; Davies et al., 1990; Raper and Kapfhammer, 1990). However, much of the in vivo roles played by all these molecules remain to be clarified. Their spatial and temporal patterns of expression suggest complex interacting effects, possibly also with soluble molecules.

Regeneration is, in part, a repetition of developmental processes. In adult vertebrates, lesioned nerve fibers regenerate extensively within the PNS, but poorly, if at all, within the CNS. Increasingly more is known about the factors and conditions that contribute to a successful reelongation of lesioned neurites over long distances in the PNS (Abrahamson et al., 1986; Daniloff et al., 1986; Ileumann et al., 1987; Rieger et al., 1988). In contrast, absence of fiber regeneration in the CNS of higher vertebrates is poorly understood.

Transplantations of pieces of peripheral nerves into various parts of the adult rat brain and spinal cord after lesion gave evidence for the capacity of central nerve fibers to regenerate (David and Aguayo, 1981; So and Aguayo, 1985). Recent studies demonstrated the existence of trophic factors (NGF or brainderived neurotrophic factor) in the CNS, also in the adult (Korsching et al., 1985; Davies et al., 1986; Shelton and Reichardt, 1986). In addition, a number of survival or neuritepromoting activities could be extracted from lesioned brain tissue (Whittemore et al., 1985, 1987; Nieto-Sampedro and Berman, 1987; Zhou et al., 1987). However, as shown by the absence of neurite ingrowth into optic nerve explants in culture in the presence of trophic factors (Schwab and Thoenen, 1985), a hypothetical lack of trophic factor production in the CNS (Ramon y Cajal, 1928) cannot entirely account for the absence of fiber tract regeneration in higher vertebrates. Instead, other constituents or compounds found in the microenvironment of reelongating nerve fibers in the CNS have to be postulated.

The roles of the different CNS glial cell types for neuronal development and regeneration are not well understood. In early development, neurons migrate along radial glia processes (Rakic, 1988). In cerebellar slices, this migration could be disturbed by the addition of antibodies against the cell adhesion molecules L1, N-CAM, or AMOG (Lindner et al., 1986; Antonicek et al., 1987). In vitro, astrocytes are good substrates for neuronal adhesion and fiber growth (Hatten et al., 1984; Fallon, 1985), in contrast to oligodendrocytes, which were shown to represent an inhibitory substrate for growing neurites (Schwab and Caroni, 1988). Subsequent observations indicated that defined com- 


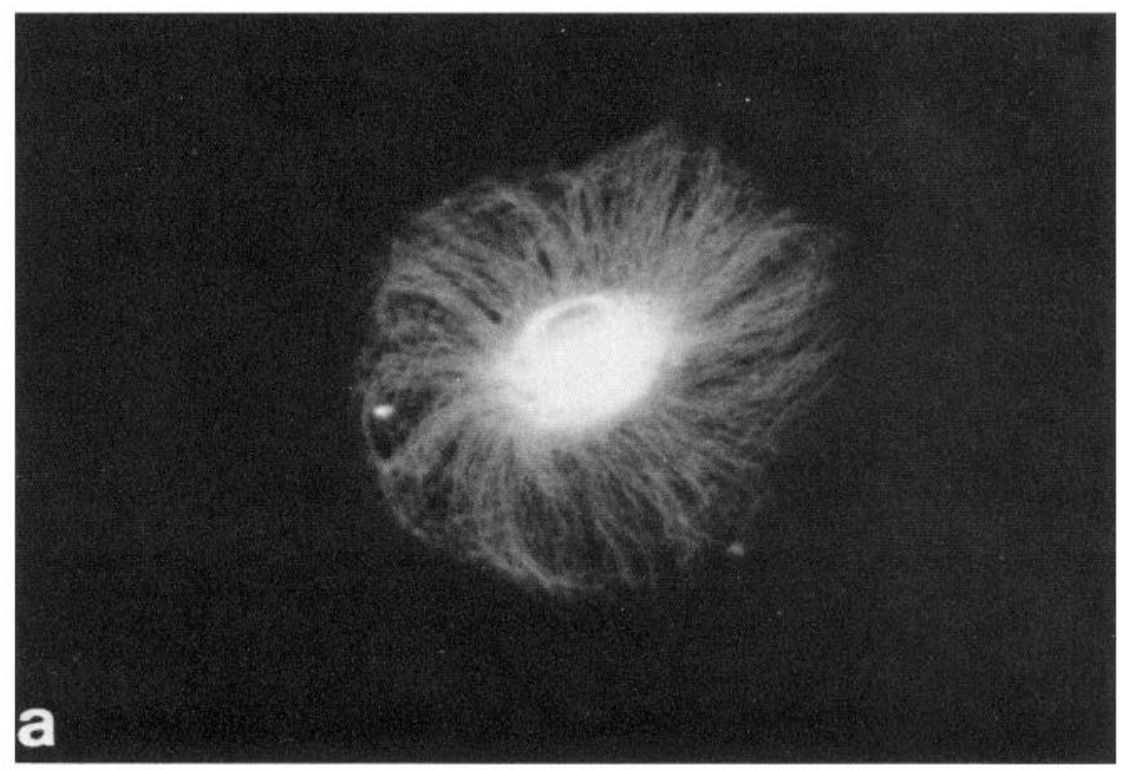

Figure 1. Immunohistochemically identified astrocyte encountered by 2 DRG growth cones (see also Fig. 2). $a$, Indirect immunofluorescence photomicrograph for GFAP. $b$, Phase-contrast photomicrograph of the same astrocyte showing growth cone (arrows)astrocyte relationship. Scale bar, 100 $\mu \mathrm{m}$.

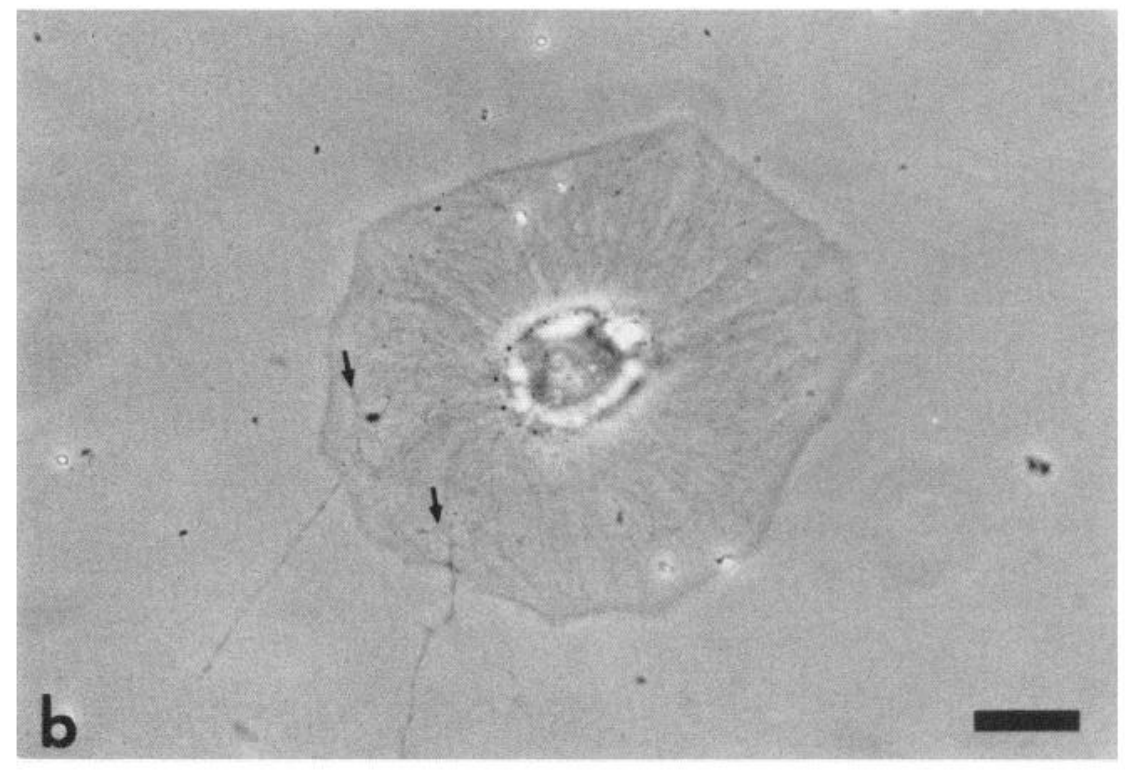

ponents of oligodendrocyte membranes and of CNS myelin exert strong inhibitory effects on growing neurites and spreading fibroblasts (Caroni and Schwab, 1988a). Two membrane proteins of CNS myelin, NI-35 and NI-250, accounted for these effects. Antibodies against these inhibitory proteins injected into adult optic nerve explants resulted in extensive neurite ingrowth into these optic nerves in vitro (Caroni and Schwab, 1988b). Recently, application of these antibodies to lesioned spinal cords in rats was shown to result in regeneration of corticospinal tract fibers also in vivo (Schnell and Schwab, 1990). Here, as a first step towards a cell biological understanding of these inhibitory effects, we have examined growth cone interactions of dorsal root ganglion (DRG) neurons with various CNS glial cell types in vitro using video time-lapse microscopy. A dramatic difference in gruwth cone behavior could be observed upon contact with astrocytes or oligodendrocytes. Whereas growth cones interacting with astrocytes maintained their normal morphology and growth velocity, firm filopodial or lamellipodial contact with differentiated oligodendrocytes resulted in a rapid and longlasting arrest of growth cone motility. This contact inhibition of growth cones was exclusively found with oligodendrocytes and could be prevented by the antibody IN-1, which neutralizes the effects of oligodendrocyte-associated inhibitory membrane proteins.

\section{Materials and Methods}

Cocultures of rat CNS glial cells with DRG neurons. Optic nerves were dissected from 6-12-d-old Lewis rats and dissociated as described by Raff et al. (1979). Plastic tissue-culture dishes were modified in order to film directly through the glass coverslips on which the cocultures were grown: holes were cut into the bottom of $35-\mathrm{mm}$ Falcon dishes, and glass coverslips were cemented over the holes from below with paraffin. Optic nerve cells were plated at low density $\left(15,500\right.$ cells $/ \mathrm{cm}^{2}$, 6000 cells/well) on a poly-L-lysine- and subsequent laminin- $(10 \mu \mathrm{g} / \mathrm{ml}$ in phosphate buffer; Collaborative Research Inc., Bedford, MA) coated coverslips. Cells were grown in enriched L15 medium (Mains and Patterson, 1973) supplemented with $5 \%$ heat-inactivated rat serum. After 2-3 d, dissociated DRG cells of newborn Lewis rats, which had been 
The Journal of Neuroscience, December 1990, 10(12) 3839
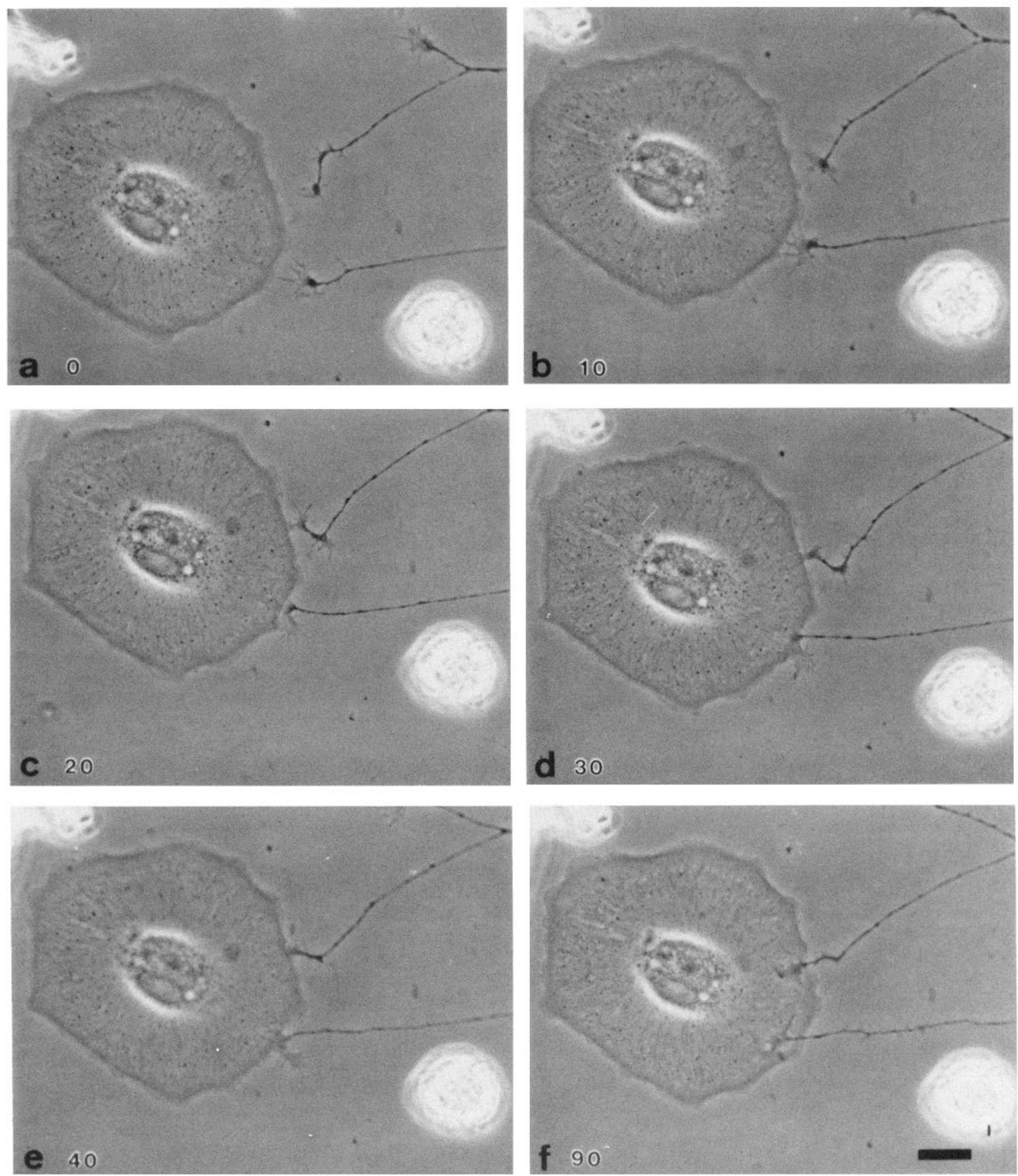

Figure 2. Photomicrographs showing specific sequences in interaction of 2 DRG growth cones with GFAP-positive astrocyte shown in Figure 1. $a$, Growth cones approaching the astrocyte. $b$ and $c$, Initial contact and interaction of short filopodial branches with the astrocyte surface. $d-f$, Subsequent movement and growth of DRG growth cones on top of the astrocyte. Times are indicated in min on the lower left of the photomicrographs. Scale bar, $100 \mu \mathrm{m}$. 


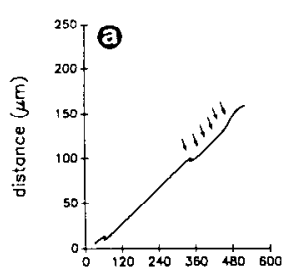

b
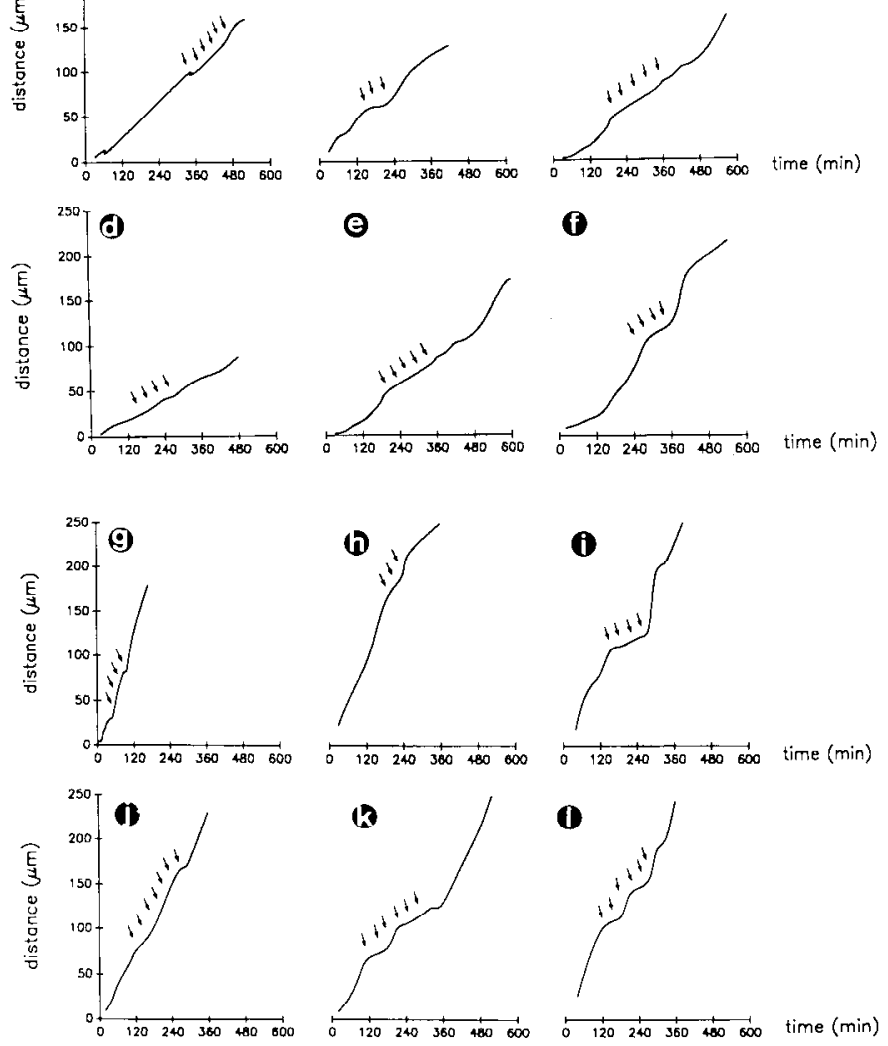

Figure 3. Velocity plots of 12 individual DRG growth cones encountering astrocytes. Positional changes of growth cones were measured in microns and plotted as distance over time. In all plots, firm lamellipodial or filopodial contacts with astrocytes are indicated by arrows. $a-f$ represent growth cones moving along $(a-c)$ or on top of $(d-f)$ astrocytes with an average velocity of $12-15 \mu \mathrm{m} / \mathrm{hr}$. Only minor changes in growth rates are seen upon contact with the astrocyte surface. In contrast, some faster-moving growth cones (average rate of $45-50 \mu \mathrm{m} / \mathrm{hr}$ ) reduce their speed by up to $25 \%$ when meeting astrocytes or during their subsequent growth along $(g-i)$ or on top of $(j-l)$ astrocytes.

preplated for $3 \mathrm{hr}$ on plastic culture dishes to reduce the amount of nonneuronal cells, were added to the glial cell cultures $\left(7800\right.$ neurons $/ \mathrm{cm}^{2}$, 3000 neurons/well). The same medium was used for the cocultures, with the addition of NGF (2.5 S NGF, $50 \mathrm{ng} / \mathrm{ml}$; a gift from Dr. H. Thoenen) and cytosine arabinofuranoside (Ara C; $0.25 \mathrm{~nm}$; Sigma).

Video time-lapse movies. Video time-lapse movies were taken after 12-24 hr of coculture. The medium level was reduced until only the hole over the coverslip was filled. To avoid evaporation, a silicon grease ring was put around the hole, filled up with medium, and sealed with a glass coverslip. These sealed chambers, containing about $70 \mu \mathrm{l}$ fresh, previously equilibrated medium, allowed cell survival and perfect neurite growth for up to $16 \mathrm{hr}$. Individual culture dishes were transferred onto a heating stage $\left(37^{\circ} \mathrm{C}\right)$ of an inverted Olympus IMT-2 microscope. The growth cones were viewed in phase contrast with a $40 \times$ Planapo objective (Olympus). The time-lapse video recording system consisted of an Aqua Tec SM72 CCD camera $(300 \times 300$ pixels; Aqua Tec, Kempten, FRG), a Panasonic time-lapse video recorder (Panasonic NV-

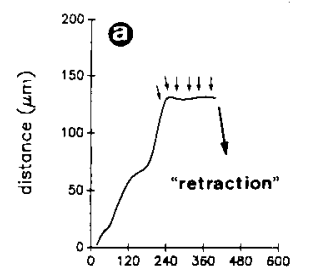

b)

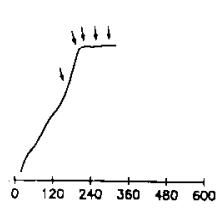

$\boldsymbol{\Theta}$
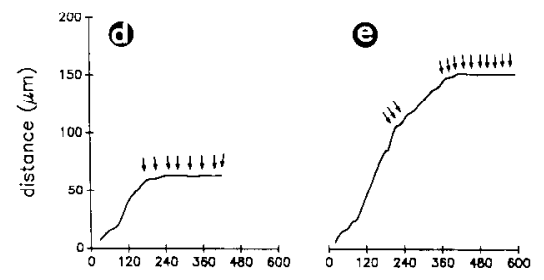

(b)
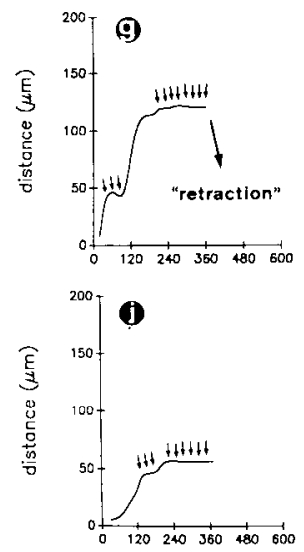

$\mathbf{k}$

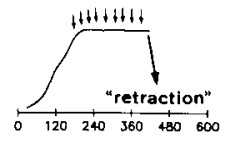

c

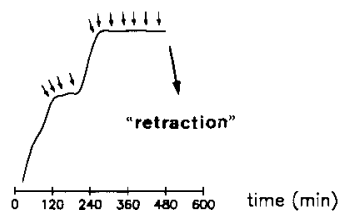

$\mathbf{f}$

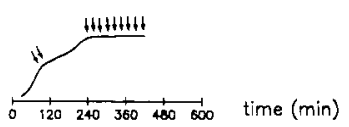

( )

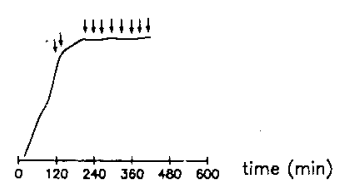

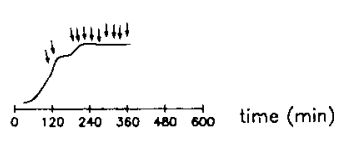

Figure 4. Velocity plots of 12 individual DRG growth cones encountering oligodendrocytes. Arrest of growth cone motility occurs when firm filopodial contacts are established with the oligodendrocytes (small arrows). Retraction of growth cones and neurites are indicated by long arrows. No obvious behavioral difference can be seen in the response of growth cones interacting with highly branched oligodendrocytes ( $a-$ $f)$ or $\mathrm{O}_{1}$-positive cells with few, thick processes $(g-l)$. Fast- $(a-c, g-i)$ and slow- $(d-f, j-l)$ moving growth cones show the same arrest response.

8051-E), and a VTE monitor. The sampling time for most movies was 3 frames $/ \mathrm{sec}$. Photomicrographs were taken either from the monitor with a Nikon FA camera on Kodak TMX 400 film or with a camera attached to the microscope on Kodak Pan 100 film.

Immunofluorescence. After recording, we identified the cells encountered by growth cones using the mouse monoclonal antibody $\mathrm{O}_{1}$ recognizing a galactocerebroside (Sommer and Schachner, 1981) as a marker for differentiated oligodendrocytes and a rabbit antiserum against glial fibrillary acidic protein (GFAP) as a marker for astrocytes (Dahl and Bignami, 1976). Before antibody incubation, the recorded cultures were washed twice with buffer-P (0.1 M phosphate buffer, $\mathrm{pH} 7.2$, containing $5 \%$ sucrose and $0.1 \% \mathrm{BSA}$ ), fixed for $15 \mathrm{~min}$ with $4 \%$ formalin in buffer-P, and rinsed again. Cocultures were then incubated for 30 min at room temperature with the $\mathrm{O}_{1}$ hybridoma supernatant (a gift from Dr. M. Schachner), rinsed, and incubated for $30 \mathrm{~min}$ with an antimouse fluorescein isothiocyanate (FITC)-linked secondary antibody (Cappel, West Chester, PA; diluted 1:100). Staining for GFAP (Dakopatts, Glostrup, Denmark; diluted 1:250) was done for 30 min on cultures previously fixed and treated with $0.1 \%$ Triton $\mathrm{X}-100$ for $5 \mathrm{~min}$.

Figure 5. A sequence of time-lapse videomicrographs showing interaction of DRG growth cone and highly branched oligodendrocyte. Initially, a fast-moving growth cone, having long, thin filopodia, can be seen approaching an oligodendrocyte $(a)$. Filopodia from this growth cone $(b$, arrow) touch the oligodendrocyte $(b, c)$ before establishing firm contact $(d)$. Additional filopodia establish permanent contact $(e$ and $f$, arrows). This sometimes results in a filopodial fascicle formation $(g)$. After $3 \mathrm{hr}$ of immobilization, however, the growth cone collapses and retracts, while remaining in contact with the oligodendrocyte via a thin stretch of cytoplasm $(h$, arrow). Times are indicated in min in the upper right of each frame. Scale bar, $100 \mu \mathrm{m}$. 

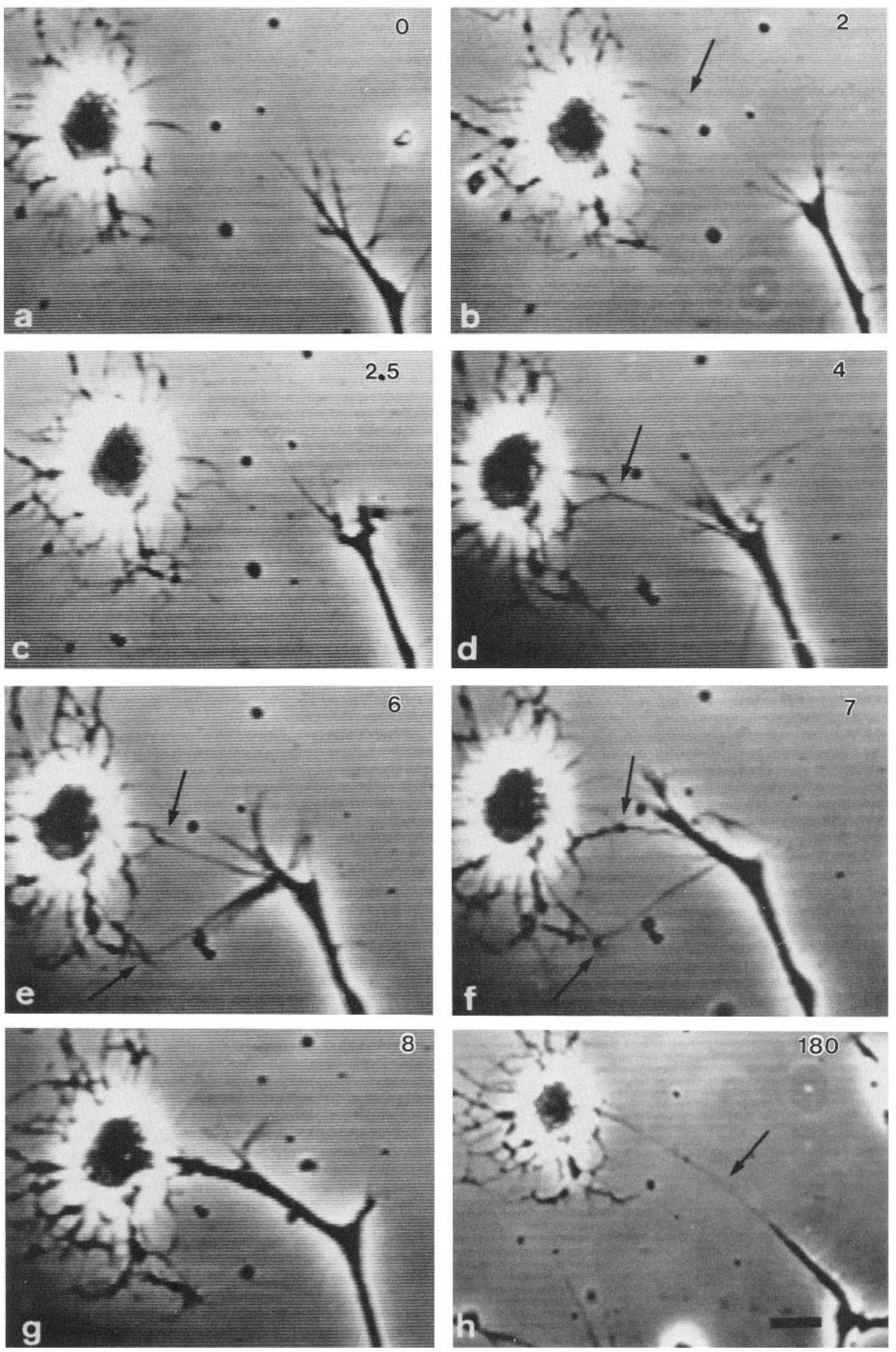

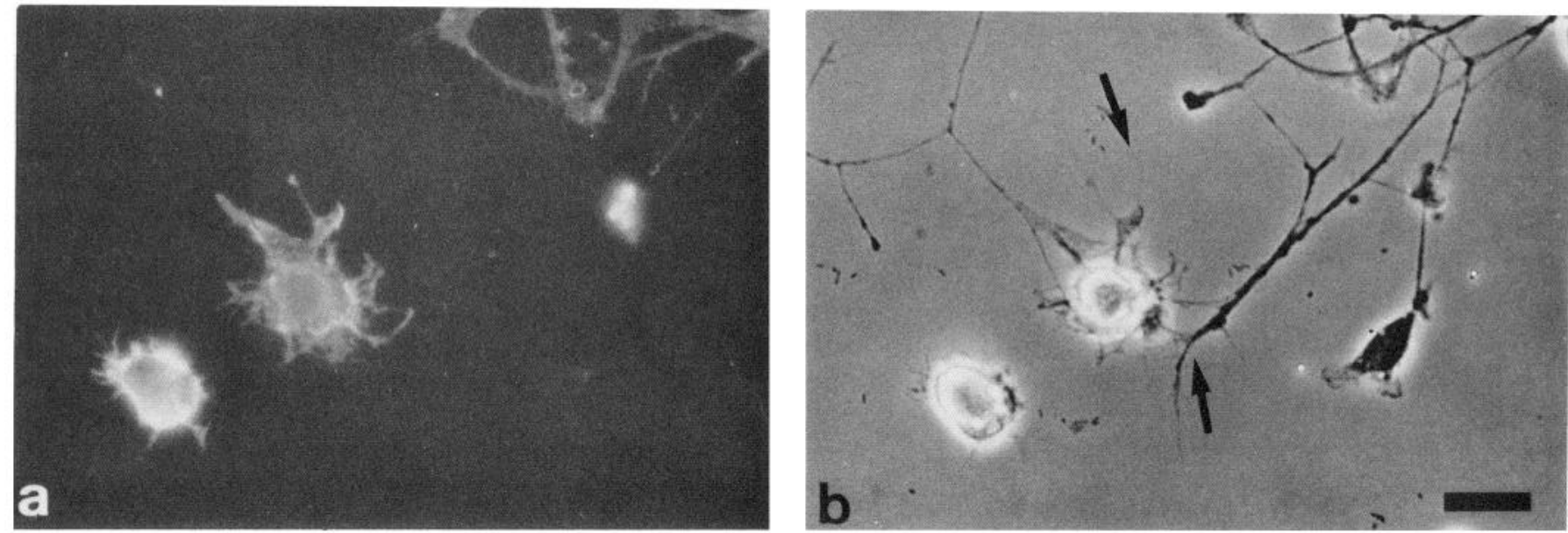

Figure 6. Immunohistochemically identified highly branched oligodendrocyte encountered by DRG growth cone. $a$, Indirect immunofluorescence photomicrograph for $\mathrm{O}_{1} . b$, Phase-contrast photomicrograph of the same oligodendrocyte, showing oligodendrocyte-DRG growth cone (arrows) relationship. Scale bar, $100 \mu \mathrm{m}$.

For visualization, the cultures were incubated for $1 \mathrm{hr}$ with an antirabbit FITC-linked secondary antibody (Miles; diluted 1:100).

Preabsorption of the cocultures with monoclonal IN-I antibodies. Prior to the addition of DRG neurons, glial cells were preabsorbed with heatinactivated, 1:2-diluted IN-1 hybridoma supernatant, directed against NI-35 and NI-250 (Caroni and Schwab, 1988b). The antibody was also present at the same dilution throughout recording. Controls were recorded in the presence of $\mathrm{O}_{1}$ hybridoma supernatant, diluted 1:2. Both these antibodies are IgMs and recognize surface epitopes on living oligodendrocytes.

Quantitative evaluation of growth cone velocities. To illustrate the growth velocities of individual growth cones before and after their interactions with glial cell surfaces, we recorded the relative position of each growth cone in relation to several reference points in 5-, 10-, 20-, or 30 -min intervals on transparent paper from the TV monitor. The positional changes were measured in microns and plotted as distances over time, using the graphic computer programs SIGMA-SCAN and SIGMA-PLOT (Jandel Scientific, 1987, Sausalito, CA). Specific events such as filopodial contacts or retracting neurites were also recorded and indicated in the graphs.

\section{Results}

\section{General observations}

Several cell types were present in short-term cultures of dissociated optic nerves of 6-12-d-old rats: flat cells representing astrocytes (GFAP positive) and fibroblasts, differentiated oligodendrocytes $\left(\mathrm{O}_{1}\right.$ positive) with various morphologies, and several types of precursor cells. The main oligodendrocyte subtype present under these culture conditions possessed a radial, highly branched, and anastomosing process network (Schwab and Caroni, 1988). This cell type is often myelin basic protein (MBP)-positive and can form myelinlike structures after longterm culture periods (Yim et al., 1986). In addition to radial, highly branched cells, $\mathrm{O}_{1}$-positive oligodendrocytes with few, thick processes also occurred, especially with laminin as a substrate. These cells were distinct from the bipolar or polygonal precursor cells by their antigenic characteristics $\left(\mathrm{O}_{1}\right.$ positive, $\mathrm{A}_{2} \mathrm{~B}_{5}$ and $\mathrm{GD}_{3}$ negative).

Dissociated rat DRG neurons were added to the low-density glial cell cultures after 2-3 d. The presence of NGF in the culture medium and the laminin substrate led to a rapid fiber outgrowth. A striking difference was observed in the growth rates of the DRG growth cones. In $40 \%$ of the observed cases, the growth cones grew with an average rate of $12-15 \mu \mathrm{m} / \mathrm{hr}$. These growth cones had extensive lamellipodia with few, short filopodia. Sixty percent of the growth cones advanced with an average rate of $45-50 \mu \mathrm{m} / \mathrm{hr}$. These growth cones showed a thin configuration and long, thin filopodia. In cocultures with dense neurite networks, the formation of windows around differentiated oligodendrocytes was seen as described previously (Schwab and Caroni, 1988).

\section{Growth cones encountering astrocytes}

To analyze the behavioral dynamics of DRG growth cones interacting with astrocytes, we have observed 31 astrocyte-growth cone encounters. Cultures were stained after recording for GFAP to determine the identity of the cells contacted by the DRG growth cones. Fifteen of the observed growth cones followed the edge of astrocytes, 12 grew on top of the astrocytes, and 4 grew under the cells. A typical encounter between an astrocyte (GFAP positive; Fig. 1) and 2 DRG growth cones is shown in Figure 2. The growth cones approached the astrocyte with a growth rate of $15 \mu \mathrm{m} / \mathrm{hr}$ (Fig. 2a) and repeatedly touched the cell surface with their short filopodia (Fig. $2 b, c$ ) over a few min. Having established firm filopodial contact (Fig. 2d), the growth cones then moved onto the astrocyte without major changes of their extended, lamellipodial morphology (Fig. 2e,f). In this particular case, the growth cones did not reduce their velocity upon contact with or during subsequent growth on top of the astrocyte.

Figure 3 shows the velocity of 12 growth cones before and during their encounter with astrocytes. The initial growth rates on laminin ranged between 12 and $15 \mu \mathrm{m} / \mathrm{hr}$ (Fig. $3 a-f$ ) or between 45 and $50 \mu \mathrm{m} / \mathrm{hr}$ (Fig. $3 g-l$ ). Slow-growing growth cones, such as the ones presented in Figure 2, did not detectably change their growth during their growth along (Fig. $3 a-c$ ) or on top (Fig. 3d-f) of the astrocytes. However, some (about $1 / 3$ ) of the fast-growing growth cones reduced their velocity by up to $25 \%$ after having established contact with the astrocyte's surface (Fig. $3 g-l$ ). Clearly, though, these results confirm the earlier reports that astrocytes are good substrates for neurite growth (Hatten et al., 1984; Fallon, 1985).

\section{Growth cones encountering oligodendrocytes}

Whereas DRG growth cones showed no or only minor changes in their motility upon interaction with astrocytes, contact with 

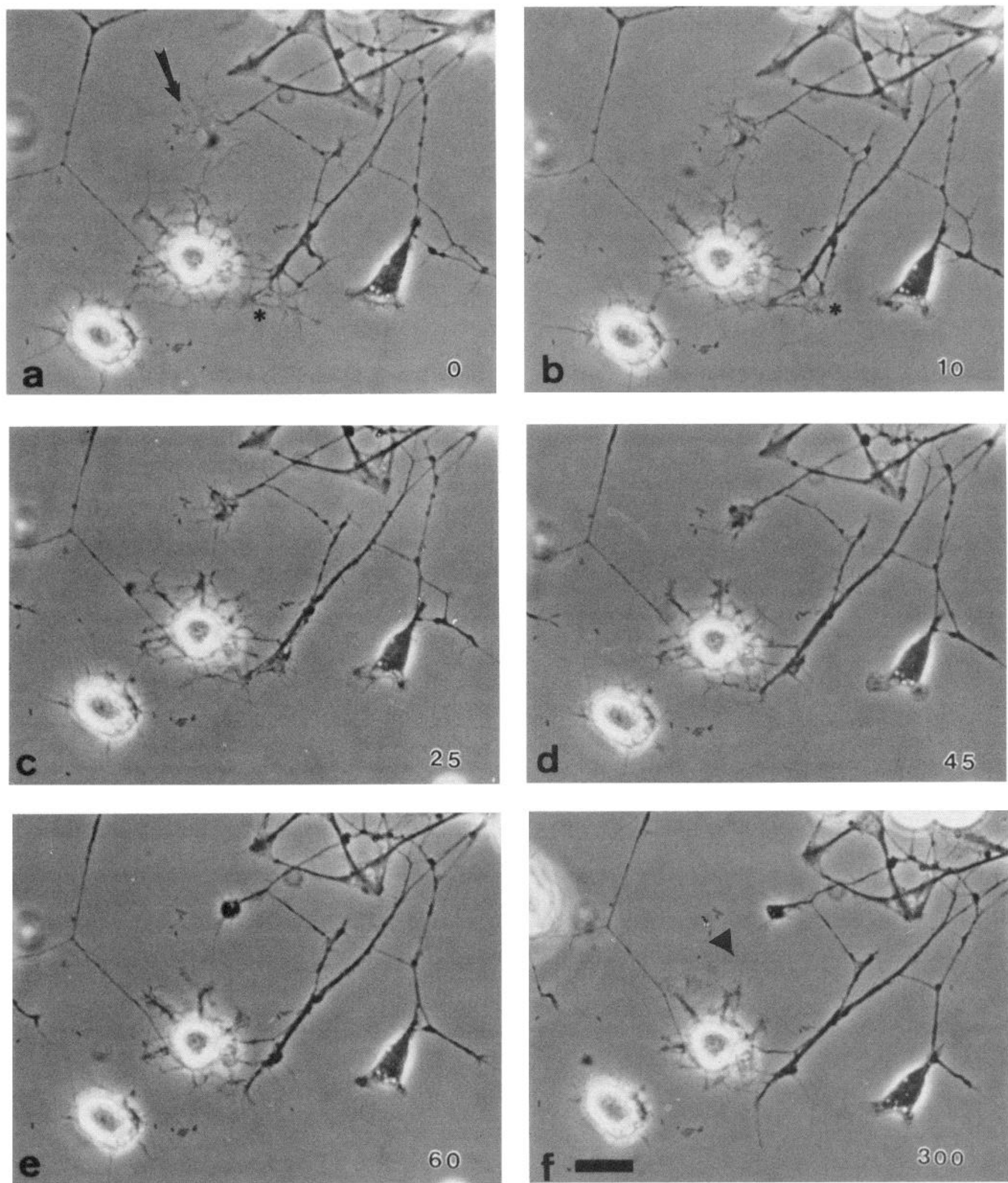

Figure 7. Sequence of phase-contrast photomicrographs showing DRG growth cones encountering oligodendrocyte shown in Figure 6. The growth cone morphologies shown in $a$ represent an intermediate (arrow) and an advanced (asterisk) stage of growth cone-oligodendrocyte contact. $b-f$, A single filopodial contact is sufficient to arrest growth cone motility and collapse growth cone structure. The various growth cones remain immobilized over the entire time of observation $(5 \mathrm{hr} ; f)$. Contact, however, remains between the oligodendrocyte and the collapsed growth cone $(f$, arrowhead $)$. Times are indicated in min on the lower right of each frame. Scale bar, $100 \mu \mathrm{m}$. 
differentiated, $\mathrm{O}_{1}-[\mathrm{GalC}$ - (galactocerebroside)] positive oligodendrocytes resulted in an arrest of the growth cones over the entire period of observation (1-6 hr). We have recorded encounters of 36 growth cones with $\mathrm{O}_{1}$-positive oligodendrocytes. In all (36/36) observed cases, stable filopodial attachment of the growth cones with the oligodendrocytes was followed by an arrest of the growth cones. In about $1 / 3$ of the observed interactions (10/36), the growth cones and the neurites eventually retracted. In these cases, the retracting growth cones often retained contacts with the oligodendrocytes; long, stretched filopodia spanned the distance between the oligodendrocyte and the growth cone, even under the considerable tension produced by the retraction. In a few cases, retracted growth cones, which have lost the connection with the oligodendrocyte, recovered after a certain lag phase: they continued their growth, provided no further contacts with oligodendrocytes occurred. Regrowing growth cones that contacted the same oligodendrocyte, which previously caused collapse and retraction, were immobilized again (data not shown).

Velocity plots of growth cones and their reaction to oligodendrocyte contacts are shown in Figure 4. Notably, the growth cone velocity often decreased immediately after stable filopodial contacts were established (Fig. 4, arrows). No obvious differences in their inhibitory effect were scen for oligodendrocytes of different morphologies (Fig. $4 a-f$, highly branched oligodendrocytes; $g-l$, $\mathrm{O}_{1}$-positive cells with few, thick processes). Both types of growth cones, the fast-growing ones (Fig $4 a-c, g-i$ ), as well as the slow ones (Fig. $4 d-f, j-l$ ), showed the same arrest responses after filopodial contact with the oligodendrocyte surface.

An example of an encounter between a growth cone and a highly branched oligodendrocyte is shown in Figure 5. Before contact, the growth cone with a long, thin conformation approached the oligodendrocyte with a velocity of $47 \mu \mathrm{m} / \mathrm{hr}$ (Fig. $5 a$ ). After single neuronal filopodia have surveyed the surface of the oligodendrocyte (Fig. $5 b, c$ ), 1 of the long, thin filopodia formed firm contact with the process network of the oligodendrocyte (Fig. 5d). Growth arrest (forward displacement) occurred simultaneously. Undirected filopodial movement continucd for some time, contacted the oligodendrocyte (Fig. $5 e$ ), and formed a filopodial fascicle (Fig. $5 f$ ). Finally, filopodial activity ceased, and all growth cone motility was completely arrested (Fig. $5 g$ ). The growth cone stayed paralyzed over several (6) hours, and finally retracted. Thin processes could be seen keeping contact with the oligodendrocyte surface (Fig. $5 h$ ).

Another interaction between growth cones and an oligodendrocyle $\left(\mathrm{O}_{1}\right.$ positive; Fig. 6$)$ is shown in Figure 7. A large growth cone, having a typical lamellipodial structure, advanced with a rate of $17 \mu \mathrm{m} / \mathrm{hr}$ until it made first filopodial contact with the cell surface (Fig. 7a). This contact of 1 or 2 filopodia led within $10 \mathrm{~min}$ to the arrest of growth cone motility and to a shrinkage of the growth cone (Fig. $7 b$ ). The growth cone slowly lost its lamellipodial configuration, started to round up (Fig. $7 c, d$ ), and completely collapsed after $60 \mathrm{~min}$ (Fig. 7e). The collapsed growth cone was still in contact with the oligodendrocyte with 1 or 2 thin filopodia after additional $4 \mathrm{hr}$ and showed no signs of recovery (Fig. $7 f$ ).

\section{Growth cones encountering oligodendrocytes in the presence of} monoclonal antibody $I N-1$

In order to determine whether preadsorption of the cocultures with antibodies neutralizing the oligodendrocyte-associated neurite growth inhibitors could prevent the motility arrest of growth cones upon contact with oligodendrocytes, we observed 10 growth cone-oligodendrocyte encounters in the presence of the monoclonal antibody IN-1 (Caroni and Schwab, 1988b). Control cultures were recorded in the presence of monoclonal antibody $\mathrm{O}_{1}$ recognizing oligodendrocyte-specific surface antigens (GalC; Sommer and Schachner, 1981). This monoclonal antibody $\mathrm{O}_{1}$ represents an optimal control because it binds specifically and at high density to oligodendrocyte membranes and, like IN-1, belongs to the IgM class.

No obvious morphological or locomotory changes of isolated glial cells or individual growth cones were seen upon addition of the hybridoma supernatants over up to $7 \mathrm{hr}$ of observation. A typical growth cone-oligodendrocyte encounter in the presence of the IN-1 antibody is shown in Figure 8. The growth cone approached the oligodendrocyte with a velocity of $13 \mu \mathrm{m} /$ hr. While surveying the cell's surface with short filopodial processes, the growth cone shrank, became long and thin, and reduced its speed for several min (Fig. 8a). However, no paralysis or retraction could be seen, and the growth cone then continued to advance with its initial growth rate onto and over the process network of the oligodendrocyte (Fig. $8 b-f$ ). Seven of 10 growth cones interacting with oligodendrocytes in the presence of IN-1 antibodies showed no visible signs of inhibition and grew along and over oligodendrocytes without major changes in their motility (Fig. $9 a-c$ ). In the remaining 3 cases, the growth cones moved onto the oligodendrocyte process network at a signifcantly slower rate (Fig. 9d,e). However, this situation, too, is different from the absence of $\mathrm{IN}-1$, where growth cones were stopped at the margin of the process network. In contrast to IN1 , the antibody $\mathrm{O}_{1}$, in spite of its strong binding to the oligodendrocyte surface, could not neutralize the inhibitory surface properties of differentiated oligodendrocytes (Fig. $9 f-h$ ).

\section{Discussion}

We have used cocultures of young rat CNS glial cells and DRG neurons to study the growth cone behavior upon contact with individual astrocytes or oligodendrocytes by video time-lapse microscopy. Measuring the growth velocity of 56 different growth cones allowed us to distinguish between 2 subgroups of growth cones: fast-growing ones $(45 \mu \mathrm{m} / \mathrm{hr})$, which represent about $60 \%$ of all observed cases and have thin growth cones with many, long filopodia, and slow-growing ones $(12 \mu \mathrm{m} / \mathrm{hr})$, which represent about $40 \%$ of the growth cones and possess extensive lamellipodia with few, small filopodia. Both types of growth cones occurred within the same culture dish. Because the pop-

Figure 8. Sequence of time-lapse videomicrographs showing encounter of DRG growth cone with highly branched oligodendrocytc in prescnce of monoclonal antibody IN-1. Contact between the growth cones (arrows) and the oligodendrocyte $(a)$, in the presence of the neutralizing antibody, does not lead to an arrest of growth cone motility $(b-f)$. Within $20 \mathrm{~min}$, the growth cones have moved under and over several processes of the oligodendrocyte $(b)$. Two hr later, the growth cones have completely crossed the processes of the oligodendrocyte $(f)$. Times are indicated in hr/ $\mathrm{min} / \mathrm{sec}$ at the upper right of each frame. Scale bar, $100 \mu \mathrm{m}$. 

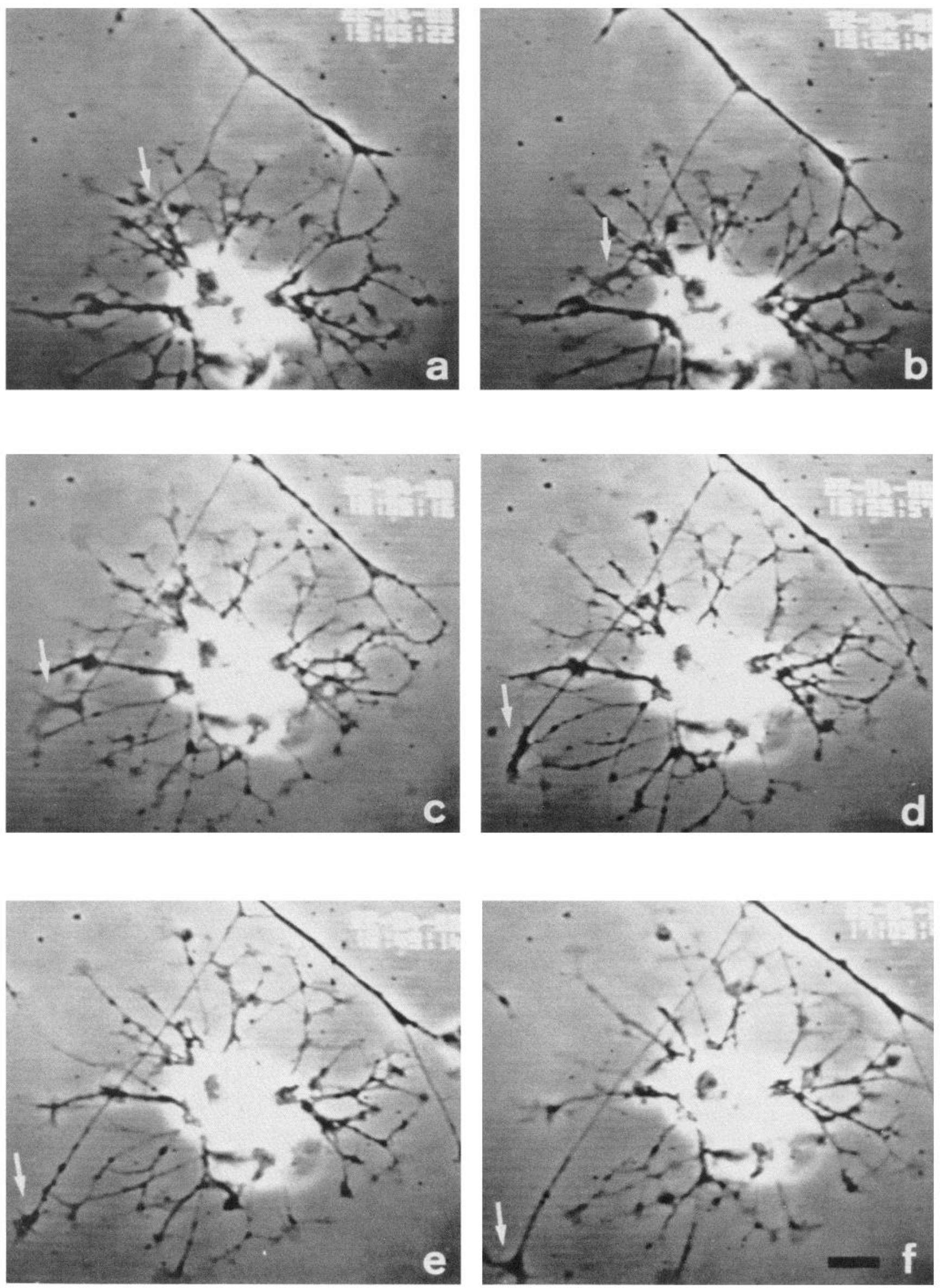

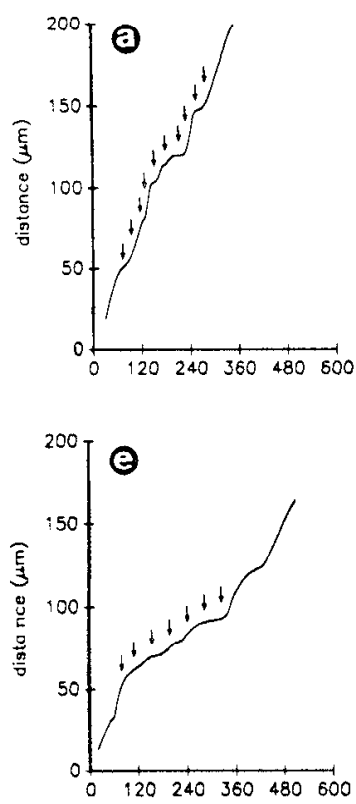

Figure 9. Eight velocity plots of DRG growth cones encountering oligodendrocytes in presence of $\mathrm{IN}-1$ or $\mathrm{O}_{1}$ antibodies. In the presence of the IN-1 antibody $(a-e)$, growth cones, though sometimes reducing their growth rate $(d, e)$, continue to move along oligodendrocyte processes $(a-e)$. However, in the presence of the $\mathrm{O}_{1}$ antibody $(f-$ $h$ ), growth cones become arrested when in contact with the oligodendrocytes.

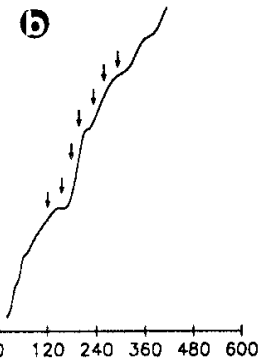

$\mathbf{f}$
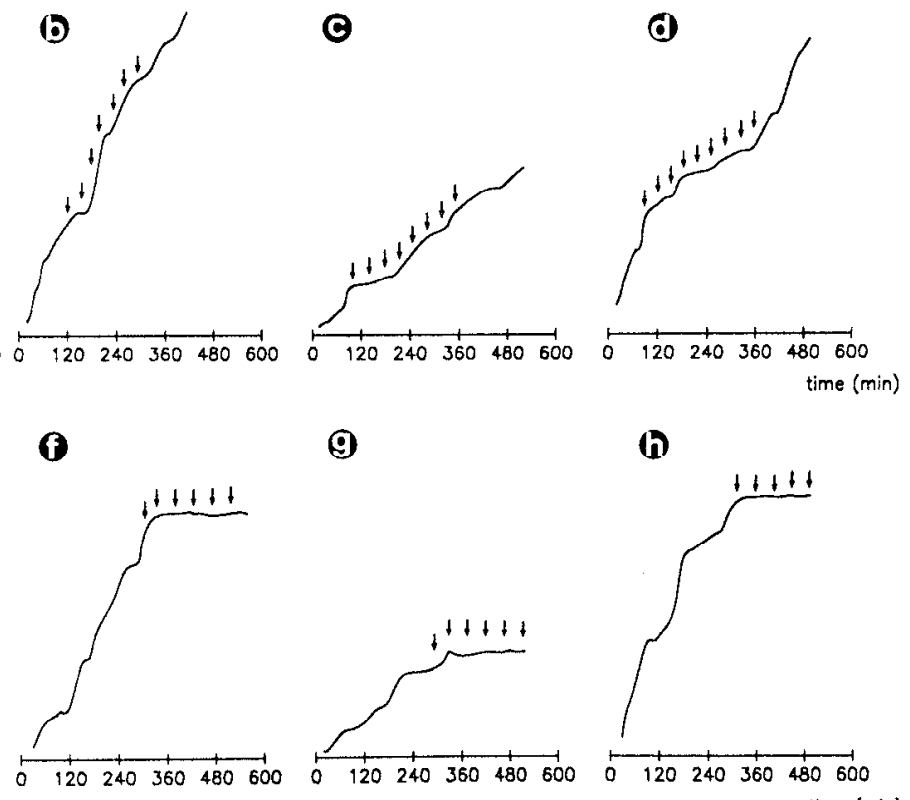

(9)

()

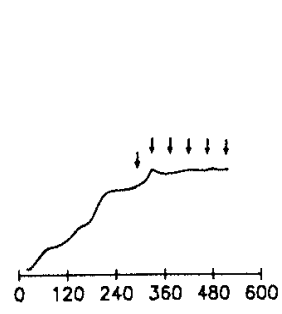

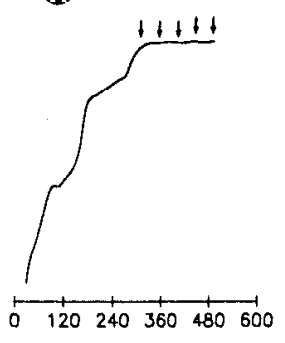

ulation of neurons within the DRG is heterogeneous, different kinds of growth cones might relate to different neuronal subpopulations. These growth cones could differ, for example, in their expression of laminin receptors, or by other properties.

When growth cones advancing on the laminin substrate contacted an astrocyte, slow-growing growth cones continued to advance without changing their velocity along or on top of the astrocytes. Thirty percent of the fast-growing growth cones, however, reduced their growth rate (by up to $25 \%$ ) when meeting astrocytes and during their subsequent growth on the astrocytes. Nevertheless, our results are in agreement with earlier observations that astrocytes are favorable substrates for elongating neurites (Hatten et al., 1984; Fallon, 1985). In contrast to astrocytes, oligodendrocytes were found to display strong inhibitory surface properties for growing neurites. Growth cones, after formation of firm filopodial contact with these cells, underwent dramatic behavioral changes. In all cases observed, their net motility was completely blocked, an arrest that persisted throughout the period of observation. In addition, $1 / 3$ of the arrested growth cones and neurites eventually retracted. Contact of filopodia with the oligodendrocyte surface sometimes persisted even under the considerable tension produced by the retraction. In addition, habituation or densensitization was not observed; retracted growth cones that lost their connection with the oligodendrocyte and recovered were immobilized again when contacting an oligodendrocyte a second time. Our results strongly indicate that the above-described inhibition of growth cone motility is based on a cell-surface interaction because the observed effect is strictly contact dependent. A diffusible factor produced by oligodendrocytes, which would act, for example, similarly to certain neurotransmitters as growth inhibitors (Haydon et al., 1984; McCobb and Kater, 1988), can therefore be excluded. The fact that growth concs arc arrested or even collapse but do not simply turn away from oligodendrocytes speaks against a mechanism based on differential adhesiveness. It is particularly noteworthy that contact of the tips of very few growth cone filopodia with the oligodendrocytes was sufficient to arrest the growth cones. This suggests the involvement of an intracellular signal transferred from the filopodial tips to the body of the growth cone, where an important part of the machincry for motility and adhesion site formation is located.

Analyzing the inhibitory substrate properties of CNS myelin, Caroni and Schwab (1988a) found that 2 membrane proteins of MW 35 and $250 \mathrm{kDa}$ are mainly responsible for this effect, which could be neutralized by monoclonal antibodies raised against these constituents (Caroni and Schwab, 1988b). In the presence of one of these antibodies (IN-1), our growth cones were no longer arrested upon contact with oligodendrocytes. Quite in contrast, they often maintained their normal speed and grew over the dense oligodendrocyte process network. This observation was never made in control cultures in the presence of the monoclonal antibody $\mathrm{O}_{1}$, though $\mathrm{O}_{1}$ antibodies strongly stain and therefore densely bind to living oligodendrocytes.

The cell biological mechanisms underlying this growth cone arrest and paralysis are still unknown. Exchange of intracellular components between growth concs and specific subsets of cells through gap junctions has been shown in the grasshopper embryo (Raper et al., 1982). However, in the rat or chick, gap junctions between growth cones and CNS glial cells have not been observed so far, neither in vitro nor in vivo. Changes of intracellular calcium in the growth cones have been related to growth cone behavior and motility, especially with regard to inhibitory effects of certain neurotransmitters (Haydon et al., 1984; McCobb and Kater, 1988). These results have demonstrated that calcium concentrations below or above a certain range greatly affect the growth cone motility (Cohan et al., 1987; Mattson and Kater, 1987; Kater et al., 1988). Whether the interaction of growth cone filopodia with oligodendrocyte membranes or with the purified inhibitory proteins NI-35 and NI250 leads to critical changes in the intracellular $\mathrm{Ca}^{2+}$ levels of growth cones is currently under investigation.

The physiological functions of the potent inhibitory effects of oligodendrocytes on neurite growth remains to be investigated. The hypothesis that inhibitory membrane components could play an important role in growth cone navigation is supported by the recent findings of several growth cone collapse-inducing activities found in the developing CNS and PNS. In vitro experiments in the developing chick retinotectal system showed 
that elongating axons from the temporal part of the retina are repulsed by components present in the membranes of the posterior tectum (Walter et al., 1987). Nasal retinal growth cones do not distinguish between anterior and posterior tectal membranes. In addition, membrane vesicles of the posterior optic tectum induce temporal growth cones to collapse and retract, whereas nasal growth cones are not affected (Cox et al., 1990). Both activities are present in the optic tectum before the generation of oligodendrocytes and disappear after embryonic day 13-14 (Arees, 1978). Kapfhammer and Raper (1987) have described the arrest and collapse of growth cones upon contact with neurites of a different type of neuron (mainly central vs. peripheral). Yet another collapse-inducing activity has been found by Davies et al. (1990) in the posterior half of somites in chicken embryos. This activity appears to be associated with components of 48 and $55 \mathrm{kDa}$. The differences in localization, cell type, and time of expression of these inhibitory and repulsive constituents indicate that they are not identical. Their functions and interactions with other inhibitory or growth-promoting components remain to be elucidated. The oligodendrocyte- and myelin-associated neurite growth inhibitors appear only late in CNS development. They exert boundary functions for a lategrowing CNS tract, the corticospinal tract (Schwab and Schnell, 1991). In the adult CNS, these inhibitory proteins could play an important role in the stabilization of fiber tracts.

\section{References}

Abrahamson IK, Wilson PA, Rush RA (1986) Production and transport of endogenous trophic activity in a peripheral nerve following target removal. Dev Brain Res 27:117-126.

Anderson H (1988) Drosophila adhesion molecules and neural development. Trends Neurosci 8:472-475.

Antonicek H, Persohn E, Schachner M (1987) Biochemical and functional characterization of a novel neuron-glia adhesion molecule that is involved in neural migration. J Cell Biol 104:1587-1595.

Arees EA (1978) Growth pattern of axons in the optic nerve of chick during myelogenesis. J Comp Neurol 180:73-84.

Caroni P, Schwab ME (1988a) Two membrane fractions from rat central myelin with inhibitory properties of neurite growth and fibroblast spreading. J Cell Biol 106:1281-1288.

Caroni P, Schwab ME (1988b) Antibody against myelin-associated inhibitor of neurite growth neutralizes non-permissive substrate properties of CNS white matter. Neuron 1:85-96.

Cohan CS, Connor JA, Kater SB (1987) Electrically and chemically mediated increases in intracellular calcium in neuronal growth cones. J Neurosci 7:3588-3599.

Cox EC, Müller B, Bonhoeffer F (1990) Axonal guidance in the chick visual system: posterior tectal membranes induce collapse of growth cones from temporal retina. Neuron 2:31-37.

Dahl D, Bignami A (1976) Immunogenic properties of the glial fibrillary acidic protein. Brain Res 116:150-157.

Daniloff JK, Levi G, Grumet M, Rieger F, Edelman GM (1986) Altered expression of neuronal cell adhesion molecules induced by nerve injury and repair. J Cell Biol 103:929-945.

David S, Aguayo AJ (1981) Axonal elongation into peripheral nervous system "bridges" after central nervous system injury in the rat. Science 214:931-933.

Davies AM, Thoenen H, Barde Y-A (1986) Different factors from the central nervous system and periphery regulate the survival of sensory neurons. Nature 319:497-499.

Davies JA, Cook GMW, Stern CD, Keynes RJ (1990) Isolation from chicken somites of a glycoprotein fraction that causes collapse of dorsal root ganglion growth cones. Neuron 2:10-19.

Edelman GM (1986) Cell adhesion molecules in the regulation of animal form of tissue pattern. Ann Res Cell Biol 2:81-116.

Fallon J (1985) Preferential outgrowth of central nervous system neurites on astrocytes and Schwann cells as compared with nonglial cells in vitro. J Cell Biol 100:198-207.

Hatten ME, Liem KM, Mason CA (1984) Two forms of cerebellar glial cells interact differently with neurons in vitro. J Cell Biol 98:193204.

Haydon PG, McCobb DP, Kater SB (1984) Serotonin selectively inhibits growth cone motility and synaptogenesis of specific identified neurons. Science 226:561-564.

Heumann R, Lindholm D, Bandtlow C, Meyer M, Radeke MJ, Misko TP, Shooter E, Thoenen H (1987) Differential regulation of mRNA encoding nerve growth factor and its receptor in rat sciatic nerve during development, degeneration and regeneration: role of macrophages. Proc Natl Acad Sci USA 84:8735-8739.

Jessell T (1988) Adhesion molecules and the hierarchy of neural development. Neuron 1:1-13.

Kapfhammer JP, Raper JA (1987) Collapse of growth cone structure on contact with specific neurites in culture. J Neurosci 7:201-212.

Kater SB, Mattson MP, Cohan C, Connor J (1988) Calcium regulation of the neural growth cone. Trends Neurosci 11:315-321.

Korsching S, Auburger G, Heumann R, Scott J, Thoenen H (1985) Levels of nerve growth factor and its mRNA in the central nervous system of the rat correlate with cholinergic innervation. EMBO J 4: 1389-1393.

Kunemund V, Jungalawa FB, Fischer G, Chou DK, Keilhauer G, Schachner M (1988) The L2/HNK-1 carbohydrate of neural cell adhesion molecules is involved in cell interactions. J Cell Biol 106: 213-223.

Lindner J, Guenther J, Nick H, Zinser G, Antonicek H, Schachner M (1986) Modulation of granule cell migration by a glia-derived molecule. Proc Natl Acad Sci USA 83:4568-4571.

Mains RE, Patterson PH (1973) Primary cultures of dissociated sympathetic neurons. J Cell Biol 59:329-347.

Mattson MP, Kater SB (1987) Calcium regulation of neurite elongation and growth cone motility. Neurosci 12:4034-4043.

McCobb D, Kater SB (1988) Membrane voltage and neurotransmitter regulation of neural growth cone motility. Dev Biol 130:599-609.

Moos M, Tacke R, Schere H, Teplow D, Fruh K, Schachner M (1988) Neural adhesion molecule $\mathrm{Ll}$ as a member of the immunoglobulin superfamily with binding domains similar to fibronectin. Nature 334: 701-703.

Nieto-Sampedro M, Berman MA (1987) Interleukin-1-like activity in rat brain: sources, targets, and effects of injury. J Neurosci Res 17: 214-219.

Raff MC, Fields KL, Hakomori R, Pruss RM, Winter J (1979) Celltype specific markers for distinguishing and studying neurons and the major classes of glial cells in culture. Brain Res 174:283-318.

Rakic P (1988) Specification of cerebral cortical areas. Science 241: 170-176.

Ramon y Cajal S (1928) Degeneration and regeneration of the nervous system (Engl ed, 1959). New York: Hafner.

Raper JA, Kapfhammer JP (1990) The enrichment of a neuronal growth cone collapsing activity from embryonic chick brain. Neuron 2:21-29.

Raper JA, Bastiani M, Goodman CS (1982) Pathfinding by neuronal growth cones in grasshopper embryos: II. selective fasciculation onto specific axonal pathways. J Neurosci 2:31-41.

Rathjen FG, Wolff JM, Frank R, Bonhoeffer F, Rutishauser U (1987) Membrane glycoproteins involved in neurite fasciculation. J Cell Biol 104:343-353.

Rieger F, Nicolet M, Pinccon-Raymond M, Murawsky M, Levi G, Edelman GM (1988) Distribution and role in regeneration of N-CAM in the basal laminae of muscle and Schwann cells. J Cell Biol 107: $707-719$.

Rutishauser U, Jessel TM (1988) Cell adhesion molecules in vertebrate neural development. Physiol Rev 68:819-857.

Rutishauser U, Gall WE, Edelman GM (1978) Adhesion among neural cells of the chick embryo. IV. Role of the cell surface molecule CAM in the formation of neurite bundles in cultures of spinal ganglia. $\mathrm{J}$ Cell Biol 79:382-393.

Schnell L, Schwab ME (1990) Axonal regeneration in the rat spinal cord produced by an antibody against myclin-associatcd ncuritc growth inhibitors. Nature 343:269-272.

Schwab ME, Caroni P (1988) Oligodendrocytes and CNS myelin are nonpermissive substrates for neurite growth and fibroblast spreading in vitro. Neurosci 7:2381-2393.

Schwab ME, Schnell L (1991) Channeling of developing rat corticospinal tract axons by myelin-associated neurite growth inhibitors. $\mathrm{J}$ Neurosci, in press. 
Schwab ME, Thoenen H (1985) Dissociated neurons regenerate into sciatic but not optic nerve explants in culture irrespective of neurotrophic factors. J Neurosci 5:2415-2423.

Shclton D, Reichardt L (1986) Studies on the expression of the $\beta$ nerve growth factor (NGF) gene in the central nervous system: level and regional distribution of NGF mRNA suggest that NGF functions as a trophic factor for several distinct populations of neurons. Proc Natl Acad Sci USA 83:2714-2718.

So KF, Aguayo AJ (1985) Lengthy regrowth of cut axons from ganglion cells after peripheral nerve transplantation into the retina of adult rats. Brain Res 328:349-354.

Sommer I, Schachner M (1981) Monoclonal antibodies $\left(\mathrm{O}_{1}\right.$ to $\left.\mathrm{O}_{4}\right)$ to oligodendrocyte cell surface: an immunocytological study in the central nervous system. Dev Biol 83:311-327.

Walter J, Kern-Veits B, Huf J, Stolze B, Bonhoeffer F (1987) Rec- ognition of position-specific properties of tectal membranes by retinal axons in vitro. Development 101:685-696.

Whittemore SR, Nieto-Sampedro M, Needels DL, Cotman CW (1985) Neuronotrophic factors for mammalian brain neurons: injury induction in neonatal, adult and aged rat brain. Brain Res 20:169-178.

Whittemore SR, Lärkfors L, Ebendal T, Holets VR, Ericsson A, Persson $H$ (1987) Increased $\beta$-nerve growth factor messenger RNA and protein levels in neonatal rat hippocampus following specific cholinergic lesions. J Neurosci 7:244-251.

Yim SH, Szuchet S, Polak PE (1986) Cultured oligodendrocytes. J Biol Chem 261:11808-11815.

Zhou FC, Auerbach S, Azmitia E (1987) Denervation of serotonergic fibers in the hippocampus induced a trophic factor which enhances the maturation of transplanted serotinergic neurons but not norepinephrine neurons. J Neurosci Res 17:235-246. 